\title{
CARACTERIZAÇÃO MORFOLÓGICA E ESTRUTURAL DE FIBRAS OCAS ASSIMÉTRICAS DE ALUMINA
}

\author{
M. G. MORIMOTO ${ }^{1}$, F. G. MARTINS ${ }^{1}$, N. M. TERRA ${ }^{1}$, L. P. BESSA $^{1}$ e M. H. M. REIS ${ }^{1}$ \\ ${ }^{1}$ Universidade Federal de Uberlândia, Faculdade de Engenharia Química \\ E-mail para contato: nat.mazza@hotmail.com
}

\begin{abstract}
RESUMO - Este trabalho avaliou a caracterização morfológica e estrutural de fibras ocas assimétricas de alumina produzidas pelo método de inversão de fase seguido de sinterização a $1350^{\circ} \mathrm{C}$. A fibra oca foi fabricada utilizando o solvente DMSO como coagulante interno com ausência de air gap, visando garantir a abertura dos filamentos na parede interna da fibra, sendo as vazões de coagulante interno e suspensão cerâmica fixadas em $15 \mathrm{~mL} \mathrm{~min}^{-1}$. Como resultado produziuse fibras ocas assimétricas, com diversos filamentos, com permeabilidade de água nas fibras igual a $16,41 \mathrm{~L} \mathrm{~h}^{-1} \mathrm{~m}^{-2} \mathrm{kPa}^{-1}$, porosidade de $40,9 \%$ e resistência mecânica de 31,72 MPa, características estas interessantes para aplicação como suporte de membranas de paládio para purificação de hidrogênio, ou como membranas para clarificação de sucos e chás.
\end{abstract}

\section{INTRODUÇÃO}

O uso de fibras cerâmicas vem ganhando interesse, pois combinam elevada resistência mecânica, térmica e mecânica, mostrando-se uma alternativa viável para as fibras poliméricas. A configuração da fibra oca é a mais promissora, pois proporciona uma área superficial mais elevada e tem uma resistência mecânica excelente, tornando-as adequadas para várias aplicações (Abdullah et al., 2016).

As fibras ocas de alumina quando fabricadas por métodos tradicionais produzem apenas morfologias simétricas, sendo necessárias etapas adicionais para garantir a estrutura assimétrica (Kingsbury et al., 2011). As fibras ocas assimétricas apresentam uma camada esponjosa (densa e simétrica) garantindo a seletividade e resistência mecânica à fibra, já a camada filamentosa (porosa) reduz a resistência à transferência de massa. O primeiro método para a produção de membranas assimétricas foi descrito por (Loeb e Sourirajan, 1963) com membranas poliméricas. Adaptando este método de inversão de fase seguido da técnica de sinterização conseguiu-se produzir fibras assimétricas em uma única etapa (Kingsbury e Li, 2009).

A produção das fibras ocas assimétricas consiste da execução de três etapas: preparação da suspensão cerâmica, extrusão da fibra oca e sinterização. Incialmente prepara-se uma suspensão de partículas cerâmicas num solvente com um ligante polimérico. Na sequência, a suspensão cerâmica é passada por uma peça extrusora, que garantirá o formato desejado de fibra oca, e através da inversão de fase do ligante polimérico (através de troca com um nãosolvente) durante a moldagem ou fiação, as partículas cerâmicas são imobilizadas. Este método pode formar precursores de membrana com morfologias específicas e propriedades de 
superfície que podem ser adaptadas. Em seguida, é necessária a calcinação e sinterização para remover todos os orgânicos do precursor de membrana e consolidar a estrutura da membrana e a resistência mecânica, respectivamente (Liu et al., 2003; Kingsbury e Li, 2009; Lee et al., 2014).

O objetivo deste trabalho foi a avaliação das características de fibras ocas assimétricas produzidas com solvente dimetilsulfóxido (DMSO) como coagulante interno. As fibras ocas foram caracterizadas de acordo com sua morfologia, permeabilidade de água, porosidade e resistência mecânica.

\section{MATERIAIS E MÉTODOS}

\subsection{Preparo das fibras ocas}

As fibras ocas assimétricas de alumina foram fabricadas segundo o método de inversão e sinterização descrito em por (Kingsbury e Li, 2009) e (Tan et al., 2001). Como material cerâmico, utilizou-se óxido de alumínio em pó $(1,0 \mu \mathrm{m}$, alpha, 99,9\% base metálica, área superficial 6-8 $\mathrm{m}^{2} \mathrm{~g}^{-1}$ ) Alfa Aesar. Primeiramente, 0,4\% (em peso) do aditivo (Arlacel 170, Croda Brasil) foi dissolvido em 36,1\% (em peso) do solvente (Dimetilsulfóxido (DMSO), Vetec) e então se adicionou 58\% (em peso) do óxido de alumínio. Esta mistura foi agitada por no mínimo $48 \mathrm{~h}$ em um agitador rotativo. Em seguida, adicionou-se o polímero aglutinante (Polietersulfona (PESf), Veradel 3000P, Solvay) e a suspensão resultante foi agitada por mais $48 \mathrm{~h}$.

Antes do processo de fiação, a suspensão cerâmica foi desgaseificada sob vácuo por $2 \mathrm{~h}$. O processo de fiação das fibras foi feito em uma peça extrusora com dois canais através dos quais escoam a suspensão cerâmica e o líquido interno responsável pela precipitação da solução e pela manutenção do lúmen interno da fibra nascente. DMSO puro foi utilizado com coagulante externo. As vazões do coagulante interno e da suspensão cerâmica na extrusão foram iguais a $15 \mathrm{~mL} \mathrm{~min}^{-1}$, com ausência de air gap (distância entre a saída da extrusora e o banho de coagulação). Antes do processo de sinterização em mufla, as fibras foram distendidas manualmente e secas em temperatura ambiente durante $48 \mathrm{~h}$. Em seguida, as fibras foram sinterizadas em mufla (Elite, Model TSH $17 / 75 / 450$ ) a $1350{ }^{\circ} \mathrm{C}$.

\subsection{Caracterização das fibras ocas}

Microscópio Eletrônico de Varredura (MEV): As fibras ocas assimétricas de alumina foram caracterizadas segundo sua morfologia e estrutura usando um microscópio eletrônico de varredura (Carl Zeiss Modelo EVO MA 10).

Permeabilidade: As fibras ocas produzidas foram caracterizadas segundo a permeabilidade de água a temperatura ambiente. Para estas medidas de fluxo, as fibras foram coladas em suporte de aço inoxidável usando cola a base de resina epóxi (Araldite ${ }^{\circledR}$ ) com uma das extremidades selada com a mesma resina. As medidas de fluxo de água foram realizadas utilizando-se uma bomba de deslocamento positivo para aumento da pressão na transmembrana e a massa de permeado foi medida em intervalos de tempos regulares.

$$
J=\frac{m}{A \cdot t}
$$


Onde $\mathrm{J}$ é o fluxo $\left(\mathrm{kg} \mathrm{m}^{-2} \mathrm{~s}^{-1}\right)$, $\mathrm{m}$ é a massa de permeado $(\mathrm{kg})$, A é a área superficial da fibra $\left(\mathrm{m}^{2}\right)$ e $\mathrm{t}$ é o tempo de coleta do permeado (s). A área superficial da fibra foi calculada de acordo com a Equação (2), conforme sugerido por (Tan et al., 2005):

$$
A=\frac{2 \pi L\left(\mathrm{r}_{o}-\mathrm{r}_{i}\right)}{\ln \left(\mathrm{r}_{o} / \mathrm{r}_{i}\right)}
$$

Onde L é o comprimento da fibra e $r_{o}$ e $r_{i}$ são os diâmetros externo e interno, respectivamente.

Porosidade: A porosidade da membrana foi calculada utilizando um método gravimétrico. A membrana foi colocada de molho em água deionizada por 24 horas. Após esse tempo, o peso da fibra molhada era obtido $\left(m_{w e t}\right)$, e a membrana passava outras 24 horas na estufa a $110^{\circ} \mathrm{C}$. A massa da membrana seca era obtida $\left(m_{\text {dry }}\right)$, e desse modo a porosidade foi calculada usando a Equação (3):

$$
\varepsilon=\frac{\Delta m}{V \rho_{\mathrm{H}_{2} \mathrm{O}}} \times 100 \%=\frac{m_{w e t}-m_{d r y}}{\frac{\pi}{4}\left(d_{O}^{2}-d_{i}^{2}\right) l \rho_{\mathrm{H}_{2} \mathrm{O}}} \times 100 \%
$$

Onde $\mathrm{m}_{\text {wet }} \mathrm{e} \mathrm{m}_{\text {dry }}$ denota o peso (g) da membrana molhada e da membrana seca,

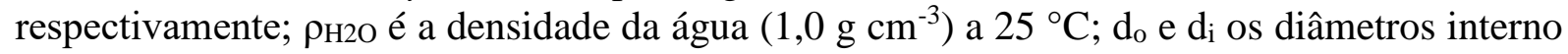
e externo da fibra oca $(\mathrm{cm})$ e 1 é o comprimento da fibra oca $(\mathrm{cm})$.

Resistência mecânica: A resistência mecânica das fibras foi determinada pelo teste de flexão em três pontos usando o equipamento Instron Model 9600 equipado com uma célula de $5 \mathrm{kN}$. A resistência à flexão $\left(\sigma_{\mathrm{F}}\right)$ de cada fibra oca individual foi calculada usando a Equação (4), proposta por (Liu et al., 2003):

$$
\sigma_{F}=\frac{8 F L D}{\pi\left(D^{4}-d^{4}\right)}
$$

Onde, F é a medida da força em que a fratura ocorreu (N), L, D e d são o comprimento, o diâmetro externo e interno da fibra, respectivamente.

\section{RESULTADOS E DISCUSSÃO}

A Figura 1 apresenta as micrografias obtidas a partir do MEV com a morfologia da fibra oca de alumina fabricada.

A fibra apresentou diâmetros interno e externo de 2,2 e 3,0 mm (Figura 1A), respectivamente, sendo então caracterizadas como fibra oca. Esta geometria apresenta a vantagem do aumento da relação área filtração por área do módulo. Além disso, observada a formação da estrutura de poros assimétrica (Figuras 1A e 1B). Atingiu-se, portanto, o objetivo proposto de fabricar fibras com estrutura de poros assimétrica em uma única etapa de fabricação, mostrando que a formulação da suspensão cerâmica e os parâmetros de extrusão foram ajustados corretamente. O processo de inversão de fases, onde o agente coagulante (água) provocou a coagulação do polímero, ocorreu de forma eficiente. A sinterização da fibra 
a $1300^{\circ} \mathrm{C}$, aplicando um patamar de temperatura intermediário de $600^{\circ} \mathrm{C}$ durante $2 \mathrm{~h}$, garantiu a eliminação do polímero e a sinterização do material cerâmico, deixando os filamentos formados abertos. Na Figura 1(B) pode-se destacar a formação de duas camadas de filamentos, uma com filamentos mais estreitos (mais externa) e outra com filamentos mais abertos (mais interna). Como se utilizou solvente (DMSO) como fluido interno não houve coagulação do polímero na parte interna da fibra. Contudo, a parte externa fibra entrou em contato com água assim que saiu da peça extrusora (zero air gap) e assim, deu-se o processo de inversão de fases que provocou a formação de inúmeros filamentos com diâmetro menor. A água tende a difundir-se ao longo da espessura da fibra, alongando os filamentos formados. Contudo, devido à viscosidade da suspensão cerâmica a força de difusão da água tende a diminuir fazendo com que os filamentos formados na parte mais interna sejam mais grossos e em menor número. Como não foi utilizada água como fluido interno, a precipitação da suspensão cerâmica na parte interna foi minimizada e os filamentos formados de fora para dentro da fibra permaneceram abertos na parte interna, como mostrado na Figura 1(C). A parte externa da fibra apresentou menor porosidade, como mostrado na Figura 1(D). Esta estrutura assimétrica, porosa e com uma camada externa esponjosa, deve favorecer a utilização desta fibra em aplicações que exijam alta permeabilidade, como por exemplo, para ser utilizada como suporte para a deposição de membranas metálicas.

Figura 1 - Imagens do MEV da fibra produzida: (A) corte transversal, (B) corte axial, (C) superfície interna e (D) superfície externa da fibra.
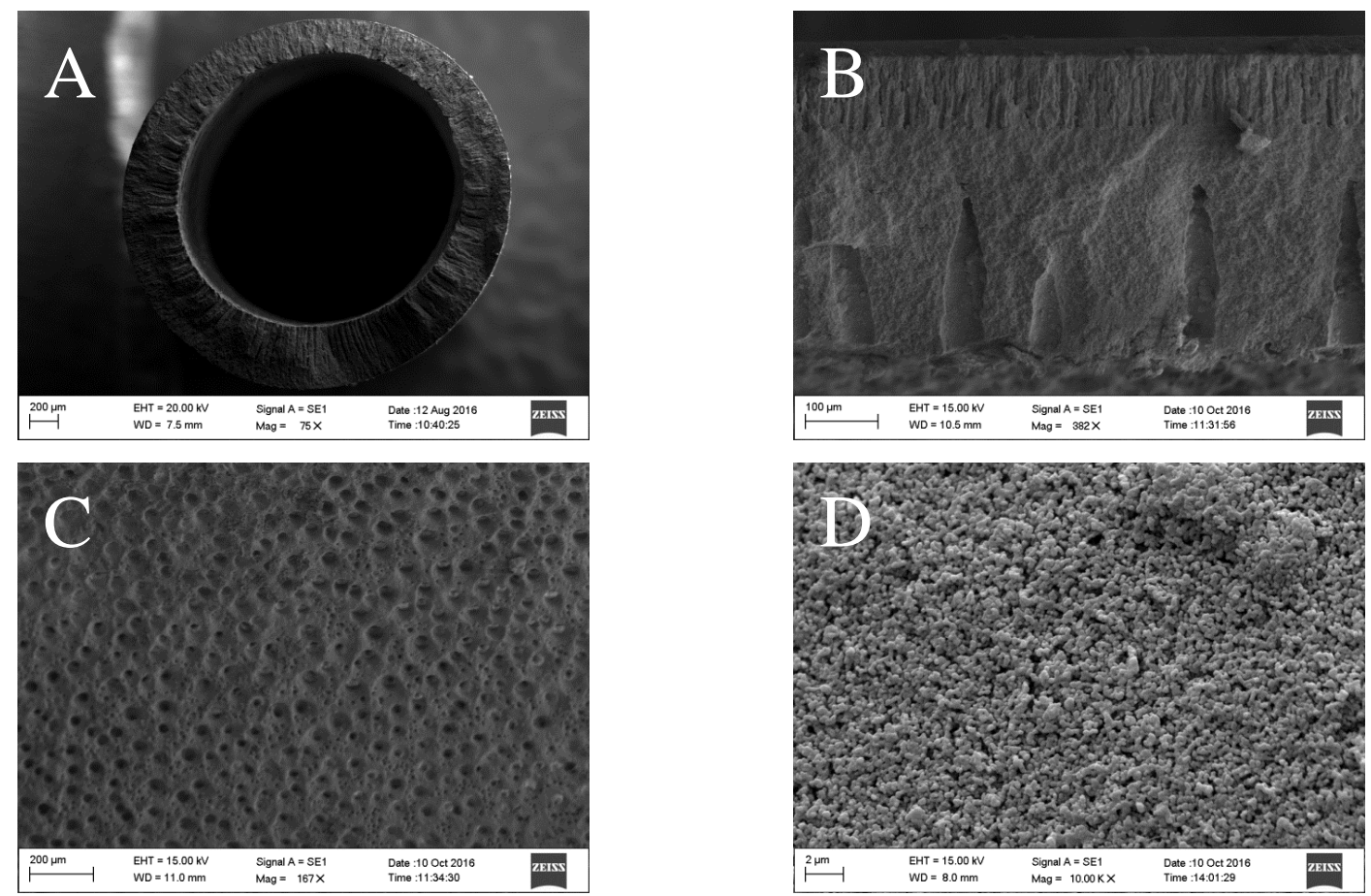

A permeabilidade de água foi avaliada apresentando valor igual a $16,41 \mathrm{~L} \mathrm{~h}^{-1} \mathrm{~m}^{-2} \mathrm{kPa}^{-1}$, de acordo com os dados de fluxo obtidos em diferentes pressões, conforme apresentado pela Figura 2. Este valor de permeabilidade encontra-se próximo aos resultados de (Terra et al., 2016), de 21,44 $\mathrm{L} \mathrm{h}^{-1} \mathrm{~m}^{-2} \mathrm{kPa}^{-1}$, em que os autores fabricaram fibras ocas de alumina utilizando 
DMSO e água como coagulante interno e ausência de air gap, e sinterizaram as fibras a $1300^{\circ} \mathrm{C}$.

Figura 2 - Fluxo de água para diferentes valores de pressão transmembrana através da fibra oca produzida.

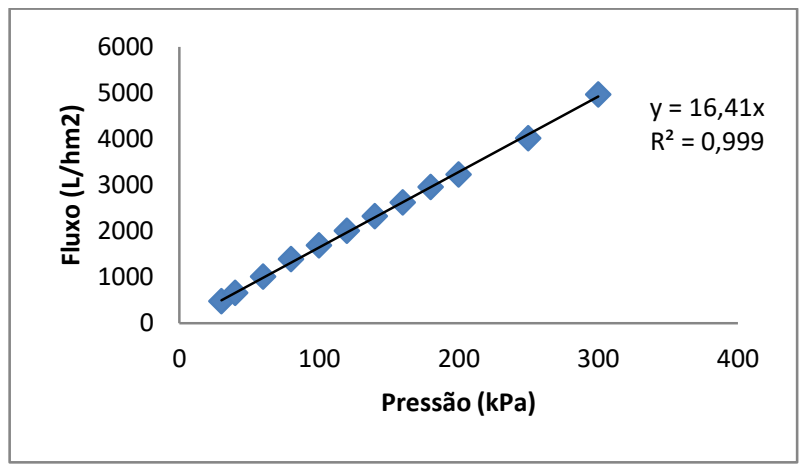

A média da porosidade das fibras ocas de alumina fabricadas foi de 40,9\% $\pm 2,3$ devido aos diversos filamentos presentes na fibra. Segundo (Virkar et al., 2000), quanto maior os poros presentes no suporte, neste caso a fibra oca de alumina, menor é a resistência ao transporte de gases, o que pode aumentar consideravelmente o fluxo de gases através da fibra oca produzida.

A resistência mecânica da fibra oca de alumina produzida foi avaliada em 31,72 MPa, valor este ligeiramente abaixo dos resultados obtidos por (Terra et al., 2016), que apresentaram valores acima de $52 \mathrm{MPa}$. Esta diferença deve-se a presença dos diversos filamentos ao longo de toda a fibra, ou seja, quanto mais filamentos, mais espaços vazios e menor a resistência mecânica. Além disso, a camada esponjosa da fibra oca foi muito fina, sendo ela a responsável pela maior resistência à flexão. A temperatura de sinterização também influencia na resistência mecânica, podendo ser aumentada uma vez que se eleve a temperatura de sinterização.

\section{CONCLUSÕES}

As fibras ocas de alumina produzidas utilizando DMSO como coagulante interno apresentaram diversos filamentos e uma fina camada esponjosa no meio da espessura da fibra. Devido aos filamentos presentes na fibra a permeabilidade de água, assim como a porosidade foram elevadas e a resistência mecânica menor dos que os valores reportados na literatura. A fibra oca produzida mostrou configuração morfológica interessante tanto para a deposição de catalisadores quanto para a deposição de membranas metálicas, como a de paládio para a purificação de hidrogênio; podendo ser aplicada também para a purificação de sucos e chás.

\section{AGRADECIMENTOS}

Os autores agradecem a FAPEMIG, CAPES e CNPq pelo suporte financeiro e ao Laboratório Multiusuário de Microscopia da Faculdade de Engenharia Química da UFU.

\section{REFERÊNCIAS}


ABDUlLAH, N.; RAHMAN, M. A.; OTHMAN, M. H. D.; ISMAIL, A. F.; JAAFAR, J.; AZIZ, A. A. Preparation and characterization of self-cleaning alumina hollow fiber membrane using the phase inversion and sintering technique. Ceramics International 42(10), p. 12312-12322, 2016.

KINGSBURY, B. F. K.; LI, K. A morphological study of ceramic hollow fibre membranes. Journal of Membrane Science 328(1-2), p. 134-140, 2009.

KINGSBURY, B. F. K.; WU, Z.; LI, K. Inorganic Hollow Fibre Membranes for Chemical Reaction. Membranes for Membrane Reactors, p. 117-153, 2011.

LEE, M.; WU, Z.; WANG, R.; LI, K. Micro-structured alumina hollow fibre membranes Potential applications in wastewater treatment. Journal of Membrane Science 461, p. 39-48, 2014.

LI, L.; CHEN, M.; DONG, Y.; DONG, X.; CERNEAUX, S.; HAMPSHIRE, S.; CAO, J.; ZHU, L.; ZHU, L.; LIU, J. A low-cost alumina-mullite composite hollow fiber ceramic membrane fabricated via phase-inversion and sintering method. Journal of the European Ceramic Society, 36(8), p. 2057-2066, 2016.

LIU, S.; LI, K.; HUGHES, R. Preparation of porous aluminium oxide $\left(\mathrm{Al}_{2} \mathrm{O}_{3}\right)$ hollow fibre membranes by a combined phase-inversion and sintering method." Ceramics International 29(8), p. 875-881, 2003.

LOEB, S.; SOURIRAJAN, S. Sea Water Demineralization by Means of an Osmotic Membrane. American Chemical Society. p. 117-132, 1963.

TAN, X.; LIU, S.; LI, K. Preparation and characterization of inorganic hollow fiber membranes. Journal of Membrane Science 188(1), p. 87-95, 2001.

TAN, X.; LIU, Y.; LI, K. Preparation of LSCF Ceramic Hollow-Fiber Membranes for Oxygen Production by a Phase-Inversion/Sintering Technique. Industrial \& Engineering Chemistry Research 44(1), p. 61-66, 2005.

TERRA, N. M.; LEMOS, C. O. T.; SILVA, F. B. D.; CARDOSO, V. L.; REIS, M. H. M. Characterisation of Asymmetric Alumina Hollow Fibres: Application for Hydrogen Permeation in Composite Membranes. Brazilian Journal of Chemical Engineering 33, p. 567-576, 2016.

VIRKAR, A. V.; CHEN, J.; TANNER, C. W.; KIM, D J.-W. The role of electrode microstructure on activation and concentration polarizations in solid oxide fuel cells. Solid State Ionics 131(1-2), p. 189-198, 2000. 